Int. J. Dev. Biol. 48: 675-678 (2004)

doi: $10.1387 / \mathrm{ijdb} .041849 \mathrm{ks}$

Short Communication

\title{
MMTV-trBrca1 mice display strain-dependent abnormalities in vaginal development
}

\author{
KAYLENE J. SIMPSON ${ }^{1, \#, ~ M A S ~ R . ~ W A T I 2 ~}{ }^{2}$ ANDREW J. DEANS ${ }^{3}$, GEOFFREY J. LINDEMAN ${ }^{4}$ \\ and MELISSA A. BROWN*,2 \\ ${ }^{1}$ Department of Biochemistry and Molecular Biology, University of Melbourne, Victoria, Australia, ${ }^{2}$ Department of Biochemistry and \\ Molecular Biology, University of Queensland, St Lucia, Queensland, Australia, ${ }^{3}$ Molecular Oncology Laboratory, Trescowthick Research \\ Laboratories, Peter MacCallum Cancer Institute, East Melbourne, Australia and ${ }^{4}$ VBCRC Laboratory, Walter and Eliza Hall Institute of \\ Medical Research, Parkville, Victoria, Australia
}

\begin{abstract}
The breast cancer susceptibility gene Brca 1 encodes a large multi-functional protein which is implicated as a caretaker of the genome, through its role in regulation of DNA damage response pathways, including apoptosis. Here we show that in mice expressing a dominantnegative Brca1 transgene on a BALB/c background, vaginal entrance remodeling is inhibited, and that the incidence of this phenotype is increased on a p53 +/- genotype. Given that this developmental process is mediated primarily by apoptosis, we hypothesized that disruption of BRCA1 may confer a resistance to apoptosis in normal epithelial cells. Consistent with this, we show that expression of this transgene in vitro leads to resistance to ionizing radiation induced cell killing in mammary epithelial cells. This is the first time that BRCA1 has been implicated in an apoptosismediated normal developmental process.
\end{abstract}

KEY WORDS: BRCA1, mouse, imperforate vagina, apoptosis

The tumor suppressor gene BRCA1encodes a large multi-functional protein which has been termed a caretaker of the genome through its role in maintaining genomic integrity by regulation of DNA damage response, transcription, cell cycle and apoptosis (reviewed in Rosen et al., 2003). Given the role of BRCA1 in embryonic and mammary development, we sought to determine whether Brca1 has a role in coordinating other normal developmental processes. Specifically, we investigated the effects of expressing a dominant-negative mutant of Brca1 in transgenic mice, under the control of the MMTV promoter, in various tissues and in cell-lines. We (Brown et al., 2002) and others (e. g. Fan etal., 2001) have demonstrated that this mutant is able to abrogate many normal functions of BRCA1. The MMTV promoter directs expression predominantly to the mammary gland, however MMTV-driven transgenes are also expressed in many other tissues (Choi et al., 1987).

On a C57BI/6 x CBA background MMTV-trBrca1 mice display a defect in mammary development with no observable histological defects in other organs (Brown et al., 2002). On a C57BI/6 x CBA x $B A L B / c$ background however, a failure of vaginal opening was observed in $11.5 \%$ of MMTV-trBrca1 mice (Fig. 1A, Table 1). The phenotype was first apparent around the age of eight to 12 weeks, i. e. during or after puberty, and was not observed in wild-type litter- mates (Table 1). In these mice the vaginal entrance was completely closed with a fur covering and they exhibited a bi-lobed external genitalia reminiscent of a scrotum (Fig. 1A). These mice exhibit an extremely swollen abdomen due to the intrauterine accumulation of mucosal fluids in the absence of normal secretion. Complete excision of the reproductive tract revealed a massively distended uterus filled with secretions ranging from clear to opaque through to a dark reddish color (Fig. 1A). There was no mortality associated with this phenotype and animals lived until sacrificed with no obvious signs of distress.

To confirm that the transgene was expressed in vaginal tissue, RNA was extracted and analysed by Northern blotting. We observed expression of the Brca1 transgene in the mammary gland of all MMTV-trBrca1 mice and expression in the vaginal tissue of MMTVtrBrca1 mice with imperforate vaginas, albeit at a significantly lower level than in the mammary gland. However, expression of the transgene in the vagina was not restricted exclusively to mice exhibiting the imperforate vagina phenotype (Fig. 1B). The transgene

Abbreviations used in this paper: Brca, breast cancer; IR, ionizing radiation; MMTV, mouse mammary tumour virus. *Address correspondence to: Department of Biochemistry and Molecular Biology, University of Queensland, St Lucia, 4072, Queensland, Australia.
Fax: +61-7-3365-4699. e-mail: melissa.brown@uq.edu.au

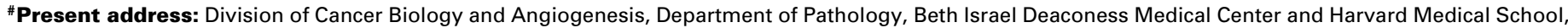
Boston, Massachusetts 02215, USA. 
$\mathbf{A}_{\text {i) }}$

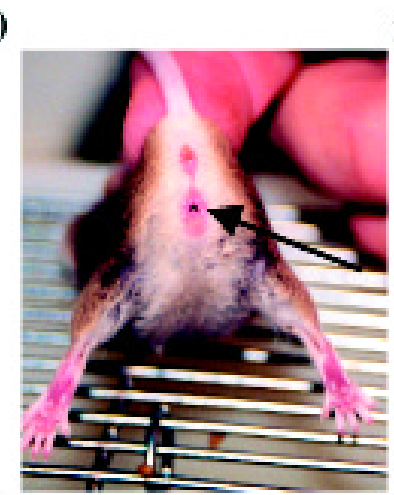

iii)

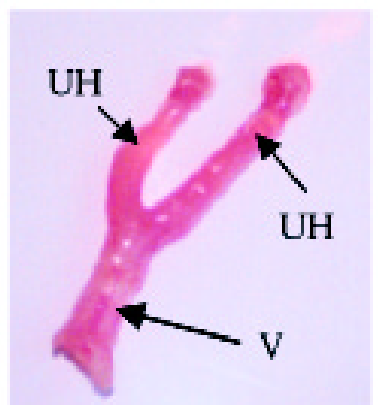

ii)

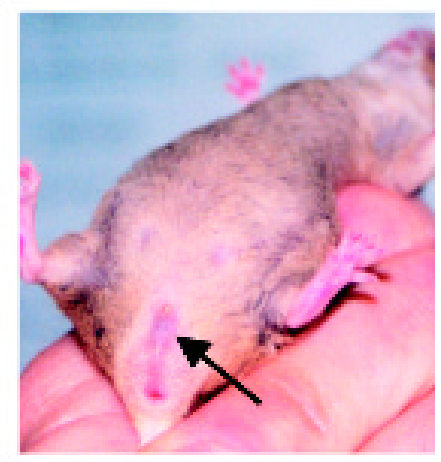

iv)

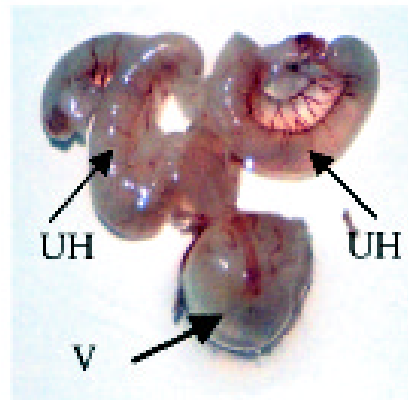

B

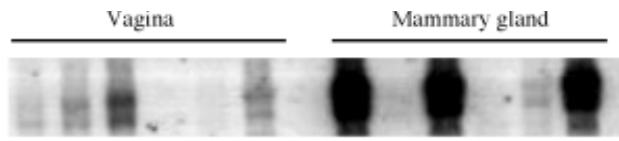

trBrcal

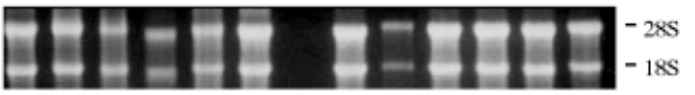

Imperforate vagins

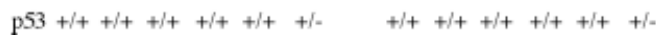

Fig. 1. Imperforate vagina in MMTV-trBrca 1 mice and examination of transgene expression levels in vaginal tissue. (A) Physical appearance of normal and affected individuals. (i) A wild-type mouse with a normal vaginal entrance as indicated by an arrow (nine weeks of age). (ii) External appearance of the imperforate vagina of a 13 week old MMTV-trBrca1 $x$ p53+/- mouse, representative of the phenotype observed in MMTVtrBrca1 and MMTV-trBrca1 $\times$ p53+/- mice (Table 1). Note the swollen vaginal region (arrow) and distended abdomen. (iii) Dissected reproductive tract of a wild-type mouse at estrous (13 weeks of age). The normal vagina (V), with a clear opening at the end, and the two uterine horns (UH) are indicated. (iv) Dissected reproductive tract of a MMTV-trBrca1 x p53+/mouse, representative of the phenotype observed in MMTV-trBrca1 and MMTV-trBrca1 $x$ p53+/- mice, exhibiting a closed vagina (nine weeks of age). Note the distended fluid filled uterus and the lack of a vaginal opening (V). (B) Northern blot of total RNA $(15 \mu \mathrm{g})$ from imperforate and normal vaginas and corresponding virgin mammary glands from the same mice of the $C 57 B / / 6 \times C B A \times B A L B / C$ background. Hybridization was performed using the $1 \mathrm{~kb}$ Brca1 fragment. Genotypes are indicated and the order is repeated for each tissue type. The presence of the imperforate vagina is also indicated. The mice range in age from 7-10 months old. The two MMTV-trBrca1 transcripts (approximately 2 and $3 \mathrm{~kb}$ ) correspond to $0.995 \mathrm{~kb}$ Brca1 plus SV4O polyA sequences and reflect the alternate use of SV4O polyadenylation signals (Brown et al., 2002). Ethidium stained ribosomal bands are shown to indicate loading.

expression level in both tissues was greater than that of the endogenous Brca1 gene (data not shown).

Development of the nervous system, digits and sexual organs occurs in utero, and involves a cell eliminating apoptotic process (Jacobson etal., 1997). During sexual development, for example, the Mullerian ducts undergo programmed cell death in males while in females they go on to form the uterus and oviducts. Conversely, the Wolffian ducts progress in males to form their sexual organs while regressing in females (reviewed in Jacobson et al., 1997). Postnatally, creation of the vaginal entrance is a hormonally triggered apoptosis-dependent process occurring within a very restricted window of time at five weeks of age (Rodriguez et al., 1997). Disruption of this process may lead to an imperforate vagina.

Naturally occurring examples of imperforate vagina in mice from large breeding colonies on multiple genetic backgrounds have been reported, with the overall incidence rate over a two year period around $0.01 \%$ (Sundberg and Brown, 1994). Interestingly, the greatest incidence has been reported in BALB/cJ mice (Cunliffe-Beamer and Feldman, 1976). More recently, several groups have reported a significant incidence of this phenotype in genetically modified mice, specifically those involving manipulation of genes that regulate apoptotic pathways (Rodriguez et al., 1997; Lindsten et al., 2000). Over-expression of the anti-apoptotic gene $B c /-2$, under control of either the mouse phosphoglycerate kinase 1 promoter or the rat neuron specific promoter on a C57BI/6 background, inhibits vaginal opening in all females (Rodriguez et al., 1997). Similarly, Lindsten et al., (2000) show that deletion of both the pro-apoptotic genes Bakand Baxon a $129 \times$ C57BI/ 6 background, results in an imperforate vagina in all females, that could be alleviated by the introduction of a single wild-type allele of either gene. An imperforate vagina was observed in $30 \%$ of glypican-3 deficient mice that model the human X-linked disorder Simpson-Golabi-Behmel syndrome (Cano-Guci etal.,1999). Glypican-3, a heparan sulfate proteoglycan, is highly expressed during development and has been shown in vitroto induce apoptosis (Duenas Gonzalez et al., 1998). In these genetically modified mice, and in the data presented here, an imperforate vagina is observed as a result of expressing transgenes that are not directed specifically to the vagina, suggesting that low level expression is sufficient for aberration of apoptotic specific pathways. Together these studies indicate that the imperforate vagina phenotype is a consequence of defects in regulating apoptosis.

BRCA1 has been implicated in the regulation of apoptosis. Overexpression of full-length $B R C A 1$ in fibroblast or tumour-derived

TABLE 1

\section{INCIDENCE OF IMPERFORATE VAGINA IN DIFFERENT MOUSE STRAINS}

\begin{tabular}{|c|c|c|c|}
\hline Genotyp & & Strain & perforate vagina \\
\hline trBrca1 & p53 & & \\
\hline- & $+/+$ & $\mathrm{C} 57 \mathrm{BI} / 6 \times \mathrm{CBA}$ & $0 \%(n>100)$ \\
\hline+ & $+/+$ & $\mathrm{C} 57 \mathrm{BI} / 6 \times \mathrm{CBA}$ & $0 \%(n>100)$ \\
\hline - & $+/+$ & $\mathrm{C} 57 \mathrm{BI} / 6 \times \mathrm{CBA} \times \mathrm{BALB} / \mathrm{c}$ & $0 \%(n=37)$ \\
\hline+ & $+/+$ & $\mathrm{C} 57 \mathrm{BI} / 6 \times \mathrm{CBA} \times \mathrm{BALB} / \mathrm{c}$ & $11.5 \%(n=78)$ \\
\hline - & $+/-$ & $\mathrm{C} 57 \mathrm{BI} / 6 \times \mathrm{CBA} \times \mathrm{BALB} / \mathrm{c}$ & $0 \%(n=28)$ \\
\hline+ & $+/-$ & $\mathrm{C} 57 \mathrm{BI} / 6 \times \mathrm{CBA} \times \mathrm{BALB} / \mathrm{c}$ & $34 \%(n=32)$ \\
\hline
\end{tabular}

The incidence of imperforate vagina in first and second-generation intercrosses is expressed as a percentage of the total mice bred per genotype on the genetic backgrounds as indicated. $n>100$ indicates we have not seen this abnormal phenotype in more than 100 wild-type mice commonly bred and analyzed in our laboratory. 
epithelial cell-lines results in an increase in spontaneous and DNAdamage-induced apoptosis and the induction of apoptotic signalling molecules including GADD45 (Shao et al., 96; Fan et al., 2001, Harkin et al., 99, Thangaraju et al., 2000). Furthermore, BRCA1 mutation (Thangaraju et al., 2000) or expression of a dominantnegative BRCA1 protein (Fan et al., 2001) in tumour-derived celllines results in suppression of apoptotic responses to stress and chemo-stimulation respectively.

Given that an imperforate vagina in other mouse models has been attributed to defective apoptosis, and that BRCA1 has been implicated in apoptosis in fibroblasts and tumour-derived epithelial cells, we hypothesized that disruption of BRCA1 may also inhibit the induction of apoptosis in normal epithelial cells. To address this possibility we examined cell viability and activation of caspase-3 in response to ionizing radiation, in an immortalized normal mammary epithelial cell-line, SVCT. Pools of SVCT cells stably expressing trBRCA1 (amino acids 1-302 of human BRCA1 in the pZeo mammalian expression system) and pZeo-empty vector were generated (Fig. 2A) and subjected to increasing doses of ionizing irradiation. In pZeo control cells, there was a clear dose-response relationship with cell death reaching $90 \%$ after treatment with 8 Grays or more (Fig. 2B). In contrast, cell death was significantly lower in cells expressing trBRCA1 with no significant correlation between dose and response. The pZeo control cells showed some induction of caspase-3 cleavage after irradiation, however this was not seen to the same extent in cells expressing trBRCA1 (Fig. 2C). Densitometric analysis indicates that the induction of caspase-3 activation in trBrca1 expressing cells, relative to the $\mathrm{pZeo}$ vector control, was $73 \%$ at $5 \mathrm{~Gy}, 72 \%$ at $6 \mathrm{~Gy}$ and $65 \%$ at $7 \mathrm{~Gy}$ (data not shown). These results support the hypothesis that trBrca1 can inhibit the induction of apoptosis in normal epithelial cells. This is consistent with, although not proof of, the notion that the imperforate vagina in our mouse model is due to defective tissue apoptosis.

We only observed the imperforate vagina in the presence of $\mathrm{BALB} / \mathrm{c}$ alleles. Interestingly BALB/c mice have a defective double strand break DNA repair pathway as a result of significantly lowered DNA-Protein Kinase catalytic subunit activity by virtue of a naturally occurring polymorphism in the coding region of the Prkdcgene (Yu etal., 2001). These mice are very sensitive to ionizing irradiation and show elevated levels of genomic instability in the mammary epithelium after irradiation, a phenomenon that is in part attributed to the low expression of DNA-PKcs in the mammary gland and subsequent DNA repair deficiency (Yu et al., 2001). This raises the possibility that disabling of the DNA-PKc regulated DNA damage response puts greater pressure on BRCA1 regulated apoptosis and thus, if BRCA1 function is also limited, the consequences of disrupting this apoptotic pathway will be exacerbated.

No other instances of this phenotype have been reported in the literature for other mammary gland specific transgenes. No specific mammary gland defects or ovarian changes were observed in these virgin mice in association with this phenotype, eliminating interference in vaginal remodeling by any hormonal changes. This phenotype was not observed in MMTV-trBrca1 mice on a C57BI/6 x CBA nor an FVB/N background. Thus, this defect appears to be a consequence of expression of the trBrca1 transgene and dependent on a mixed background including BALB/c alleles.

The incidence of imperforate vagina increased to $34 \%$ in $\mathrm{p53+/-}$ MMTV-trBrca1 mice (Table 1). It is well established that BRCA1 and p53 interact at both the genetic and the biochemical level. For example, loss of p53 delays embryonic lethality in Brca1 knockout mice (Hakem et al., 1997), accelerates tumorigenesis in mammaryspecific Brca1 conditional mutant mice (Xu et al., 1999), and attenuates the elevated levels of apoptosis observed in cells from $\mathrm{Brca}^{\Delta 11}$ ${ }^{\Delta 11}$ mice (Xu et al., 2001). From these and other studies it has been suggested that disruption of $\mathrm{p} 53$ alleviates the cell cycle and apoptotic defects induced by abnormalities in BRCA1, allowing cells to continue proliferating despite accumulating genetic instability. Here we show that deletion of one p53 allele in the context of MMTV-trBrca1 expression increases the incidence of imperforate vagina three-fold. It is therefore possible that reducing p53 in these mice results in a greater retardation of the apoptotic pathway required for normal vaginal development, thus increasing the susceptibility of the double mutant mice to this phenotype.

In summary our data suggest a role for BRCA1 in regulation of normal vaginal development. They also raise the possibility that BRCA1 plays a role in apoptosis-mediated developmental events.
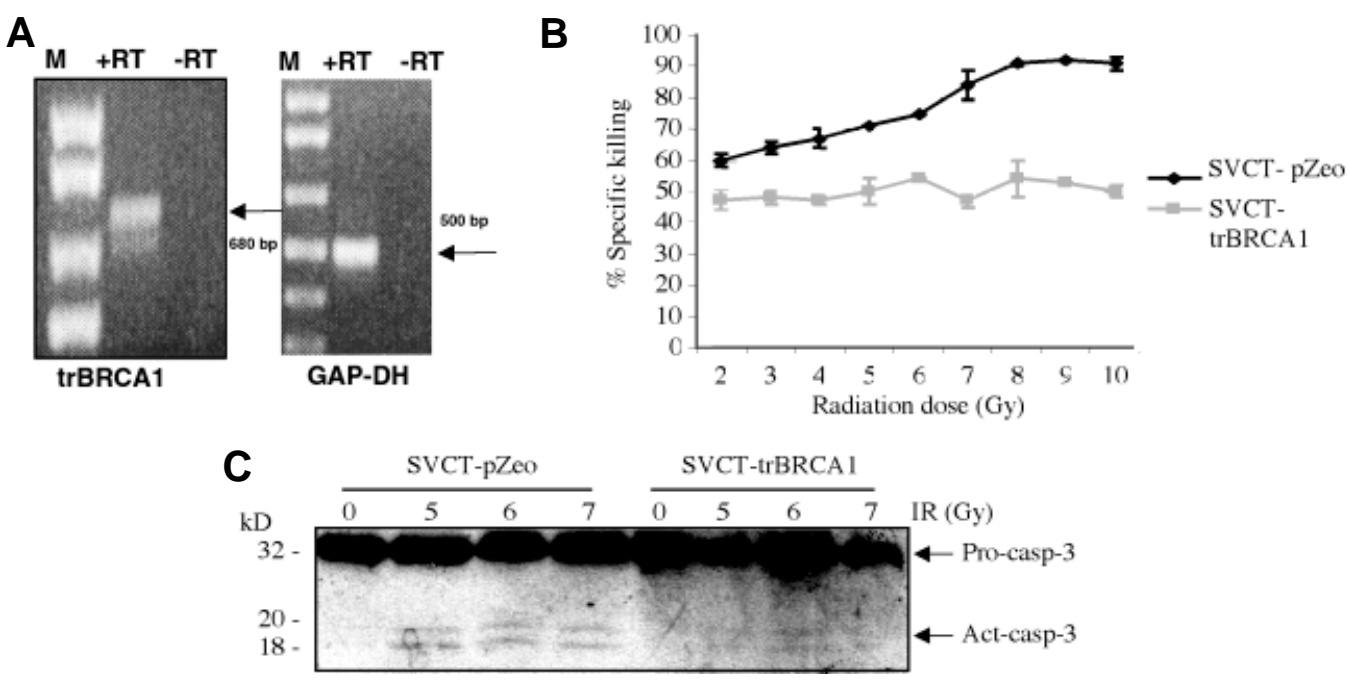

Fig. 2. SVCT cells expressing trBRCA1 exhibit apoptotic resistance and reduced caspase- 3 activation after ionizing radiation treatment. (A) Expression of trBRCA1 in human mammaryepithelialSVCT cells was determined by RT-PCR. The presence of a 680 bp band in the reverse transcriptase lane (RT) indicated expression of the transgene. The no RT control was included to show that the PCR product was mRNA specific. GAP$D H$ was included as a loading control. (B) pZeo-trBRCA1 (trBrca1) and empty vector control (pZeo) cells were subjected to increasing doses of ionizing radiation (IR; 2-10 Grays (Gy)) and the percentage of dead cells determined 72 hours post irradiation and expressed as a percentage of untreated cells. Values represent the averages from three experiments. Error bars represent the standard deviation. (C) Western analysis of total protein extracts after exposure to ionizing radiation. The pro- (procasp-3; 32 kD) and activated (act-casp-3; 20 kD) caspase-3 forms are detected by the antibody and indicated by arrows. 
This may have implications for carriers of $B R C A 1$ mutations. Interestingly, in contrast to normal individuals where pregnancy has been shown to be protective against breast cancer, pregnancy appears to increase the risk of breast cancer in BRCA1-mutation carriers (Jernstrom et al., 1999; Hartge et al., 2002). Perhaps, if apoptosis is delayed in the mammary gland of BRCA1-mutation carriers, the window of opportunity may be increased for the accumulation of mutations in already genetically unstable cells, thus increasing the risk of breast tumorigenesis.

\section{Experimental Procedures}

\section{Mouse studies}

MMTV-trBrca1 mice on a C57BI/6 $\times$ CBA background have been described previously (Brown etal., 2002). p53+/- mice on a BALB/c background (BALB/ CJ-Trp53<tmlTyj>) were obtained from Jax labs. Research was performed under approval from Animal Ethics and Experimentation Committee of the University of Melbourne, Victoria, Australia. Mice were genotyped for trBrca1 by Southern analysis of $E c o R I$ digested genomic DNA and hybridization with the $1 \mathrm{~kb}$ Brca1 fragment (Brown et al., 2002). p53 status was determined using primers for neomycin (forward, 5' GATCGGCCATTGAACAAGATGG 3 ' and reverse, 5' CCTGATGCTCTTCGTCCAGATC 3'). A 500-bp fragment was diagnostic of the deleted allele. Vaginal tissue was excised, snap frozen and RNA extracted using Trizol reagent (Life Technologies) and analysed by Northern hybridization as previously described (Brown et al., 2002).

\section{In vitro studies}

SVCT cells (ECACC \# 94122105) were grown as recommended by the supplier. SVCT cells were stably transfected with a pZeoSV-trBRCA1 construct as previously described (Brown et al., 2002). Rates of IR-induced cell killing were determined by growing triplicate cultures of cells on tissue culture plastic (seeded at $5 \times 10^{5}$ per $35 \mathrm{~mm}$ dish) for 48 hours then subjecting them to ionizing irradiation at different doses (2-10 Grays; using a ${ }^{137} \mathrm{Cs}$ source). Cells were subsequently incubated for 72 hours then fixed and stained with $0.5 \%$ crystal violet (Sigma). Samples were solubilized in 33\% acetic acid and the absorbance measured at $550 \mathrm{~nm}$ using a Spectromax 2000 platereader. Cell death was determined by the average of triplicate absorbance determinations relative to untreated control and expressed as a percentage. Values shown are averages from the results of triplicate cultures. Error bars represent the standard deviation between the results of triplicate cultures. In addition, following irradiation, total protein was extracted from duplicate samples using RIPA buffer and analyzed by western blotting using standard procedures. The anti-caspase-3 antibody (Neomarkers) was used at $1: 800$.

\section{Acknowledgements}

This work was supported by a National Health and Medical Research Council Peter Doherty Postdoctoral fellowship to KJS (\#007011), a Brunei Government Visiting Scientist Fellowship to MRWandproject grants from the Anti-Cancer Council of Victoria and the Queensland Cancer Fund to MAB. Our appreciation to Ellen Solomon for the use of the MMTV-trBrca1 mice, Max Walker formaintenance of mouse lines, RachelKoelmeyer for the stably transfected SVCT cell-lines, the ICRF for the use of the SVCT cell-line and to Philippe Bouillet, Michelle Latimer and Elizabeth Lipscomb for helpful discussions.

\section{References}

BROWN, M.A., NICOLAI, H., HOWE, K., KATAGIRI, T., LALANI, E,-N., SIMPSON, K.J., MANNING, N.W., DEANS, A.J., CHEN, P., KHANNA, K.K., WATI., M.R., GRIFFITHS, B.L., XU, C,-F., STAMP, G.W.H. and SOLOMON, E. (2002). Expression of a truncated Brca1 protein delays lactational mammary development in transgenic mice. Transgenic Res. 11: 467-478.

CANO-GUCI, D.F., SONG, H.H., YANG, H., MCKERLIE, C., CHOO, B., SHI, W.,
PULLANO, R., PISCIONE, T.D., GRISARU, S., SOON, S., SEDLACKOVA, L., TANSWELL, A.K., MAK, T.W., YEGER, H., LOCKWOOD, G.A., ROSENBLUM, N.D. and FILMUS, J. (1999). Glypican-3-deficient mice exhibit developmental overgrowth and some of the abnormalities typical of Simpson-Golabi-Behmel syndrome. J. Cell Biol. 146: 355-264.

CHOI, Y.W., HENRARD, D., LEE, I. and ROSS, S.R. (1987). The mouse mammary tumor virus long terminal repeat directs expression in epithelial and lymphoid cells of different tissues in transgenic mice. J. Virol. 61: 3013-3019.

CUNLIFFE-BEAMER, T.L. and FELDMAN, D.B. (1976). Vaginal septa in mice. Lab Animal Sci. 26: 895-898.

DUENAS GONZALEZ, A., KAYA, M., SHI, W., SONG, H., TESTA, J.R., PENN, L.Z. and FILMUS, J. (1998). OCl-5/GPC3, a glypican encoded by a gene that is mutated in the Simpson-Golabi-Behmel overgrowth syndrome, induces apoptosis in a cell linespecific manner. J. Cell Biol. 141: 1407-1414.

FAN, S., YUAN, R.-Q., MA, Y.X., MENG, Q., GOLDBERG, I.D. and ROSEN, E.M. (2001). Mutant BRCA1 genes antagonize phenotype of wild-type BRCA1. Oncogene 20: 8215-8235

HAKEM, R., DE LA POMPA, J.L., ELIA, A., POTTER, J. and MAK, T.W. (1997). Partial rescue of Brca1 (5-6) early embryonic lethality by p53 or p21 null mutation. Nat. Genet. 16: 298-302.

HARKIN, D.P., BEAN, J.M., MIKLOS, D., SONG, Y.H., TRUONG, V.B., ENGLERT, C., CHRISTIANS, F.C., ELLISEN, L.W., MAHESWARAN, S., OLINER, J.D. and HABER, D.A. (1999). Induction of GADD45 and JNK/SAPK-dependent apoptosis following inducible expression of BRCA1. Cel/97: 575-586.

HARTGE, P., CHATTERJEE, N., WACHOLDER, S., BRODY, L.C., TUCKER, M.A. and STRUEWING, J.P. (2002). Breast cancer risk in Ashkenazi BRCA1/2mutation carriers: Effects of reproductive history. Epidemiology 13: 255-261.

JACOBSON, M.D, WEIL, M. and RAFF, M.C. (1997). Programmed cell death in animal development. Cel/88: 347-354

JERNSTROM, H.C., JOHANNSSON, O.T., LOMAN, N., BORG, A. and OLSSON, H. (1999). Reproductive factors in hereditary breast cancer. Breast CancerRes. Treat 58: 295-301.

LINDSTEN, T., ROSS, A.J., KING, A., ZONG, W.-X., TAHMELL, J.C., SHIELS, H.A., ULRICH, E., WAYMIRE, K.H., MAHAR, P., FRAUWIRTH, K., CHEN, Y., WEI, M., ENG, C.M., ADELMAN, D.M., SIMON, M.C., MA, M., GOLDEN, J.A., EVAN, G., KORSMEYER, S.J., MACGREGOR, G,R. and THOMPSON, C.B. (2000). The combined functions of proapoptotic Bcl-2 family members Bak and Bax are essential for normal development of multiple tissues. Mol. Cel/6: 1389-1399.

RODRIGUEZ, I., ARAKI, K., KHATIB, K., MARTINOU, J.-C. and VASSALLI, P. (1997). Mouse vaginal opening is an apoptosis-dependent process which can be prevented by the overexpression of Bcl2. Dev. Biol. 184: 115-121.

ROSEN, E.M., FAN, S., PESTELL, R.G. and GOLDBERG, I.D. (2003). BRCA1 gene in breast cancer. J. Cell. Physiol. 196: 19-41.

SHAO, N., CHAI, Y.L, SHYAM, E., REDDY, P. and RAO, V.N. (1996). Induction of apoptosis by the tumor suppressor protein BRCA1. Oncogene 13: 1-7.

SUNDBERG, J.P. and BROWN, K.S. (1994). Imperforate vagina and mucometra in inbred laboratory mice. Lab. Animal Sci. 44: 380-382.

THANGARAJU, M., KAUFFMANN, S.H. and COUCH, F.J. (2000). BRCA1 facilitates stress-induced apoptosis in breast and ovarian cancer cell lines. J. Biol. Chem. 275: 33487-33496.

XU, X., QIAO, W., LINKE, S.P., CAO, L., LI, W.M., FURTH, P.A., HARRIS, C.C. and DENG, C.X., (2001). Genetic interactions between tumor suppressors Brca1 and p53 in apoptosis, cell cycle and tumorigenesis. Nat. Genet. 28: 266-271.

XU, X., WAGNER, K.U., LARSON, D., WEAVER, Z., LI, C., RIED, T., HENNIGHAUSEN, L., WYNSHAW-BORIS, A. and DENG, C.X. (1999). Conditional mutation of Brca1 in mammary epithelial cells results in blunted ductal morphogenesis and tumour formation. Nat. Genet. 22: 37-43.

YU, Y., OKAYASU, R., WEIL, M.M., SILVER, A., MCCARTHY, M., ZABRISKIE, R., LONG, S., COX, R., and ULLRICH, R.L. (2001). Elevated breast cancer risk in irradiated BALB/c mice associates with unique functional polymorphism of the Prkd (DNA-dependent Protein Kinase Catalytic Subunit) gene. Cancer Res. 61: 1820-1824.

Received: February 2004 Reviewed by Referees: March 2004 Modified by Authors and Accepted for Publication: May 2004 Edited by: Patrick Tam 